intestinal haemorrhage. The basic aims of the team were to provide early endoscopy for patients suspected of having had an acute upper gastrointestinal bleed and subsequently to manage such patients as a cooperative medical and surgical venture with total continuity of care.

In the three years 1983-5 haematemesis team members performed endoscopy in 1574 patients with clinical evidence of upper gastrointestinal haemorrhage. The overall hospital mortality for this group was $3.9 \%$. Bleeding from a gastric ulcer carried an overall mortality of $4 \cdot 8 \%$, while duodenal ulcer haemorrhage carried an overall mortality of $1.9 \%$. Clearly, no single factor can claim total responsibility for the striking improvement in our hospital mortality for acute upper gastrointestinal haemorrhage. We believe, however, that the team approach, which we have now used for 10 years, has contributed very significantly to our results.

Western Infirmary, Glasgow G11 6NT

W R MURRAY G G BIRNIE

\section{Asymptomatic carotid stenosis: spare the knife}

SIR,-Dr Peter Sandercock (30 May, p 1368) discusses the case against carotid endarterectomy for asymptomatic carotid bruit and comments that in the United Kingdom this operation is performed mostly for symptomatic carotid disease.

It has been established that $98 \%$ of vascular surgeons in the United Kingdom (in 1984) rarely or never peformed carotid endarterectomy for asymptomatic bruit, and I suspect that in Britain Dr Sandercock is preaching to the converted. ${ }^{1} \mathrm{He}$ also makes the point that carotid angiography is itself hazardous and that some patients may undergo such studies because "the facilities for ultrasound assessments are not widely available in the United Kingdom." This is not so. Of the 40 surgeons in this country who performed more than 10 carotid endarterectomies in 1984 and who were responsible for $1134(83 \%)$ of the total operations done in that year, no fewer than $33(83 \%)$ used ultrasonography as a screening test. ${ }^{2}$ They did this for symptomatic disease, and I would submit that for asymptomatic disease their use of ultrasonography would be even more pronounced. The few surgeons who did not use ultrasonography generally used the less hazardous digital subtraction angiography rather than conventional angiography in their assessment of carotid artery disease. ${ }^{3}$

In summary, I believe that non-invasive screening is the usual technique used by vascular surgeons in the United Kingdom to assess a patient with asymptomatic carotid bruit. Few surgeons would, in any event, advocate angiography (conventional or otherwise) for patients who were not about to undergo arterial reconstruction, and the evidence is that such reconstructions, in the case of the carotid artery, are rare on this side of the Atlantic.

Nuffield Department of Surgery,

J A MURIE

University of Oxford

John Radcliffe Hosp
Oxford OX3 9DU

1 Murie JA, Morris PJ. Carotid endarterectomy in Great Britain and Ireland. Br $\mathcal{F}$ Surg 1986;73:867-70.

2 Murie JA, Morris PJ. Arterial assessment before carotid endarterectomy: current practice in Great Britain and Ireland. endarterectomy: current practice in $\mathrm{G}$
$\mathcal{f}$ Cardiovasc Surg (Torino) (in press).

f Cardiovasc Surg (Torino) (in press).
3 Reilly LM, Ehrenfeld WK, Stoney RJ. Carotid digital subReilly LM, Ehrenfeld WK, Stoney RJ. Carotid digital sub-
traction angiography: the comparative roles of intra-arterial and intravenous imaging. Surgery 1984;96:909-17.

SIR,-Most vascular surgeons already spare the knife in patients with asymptomatic carotid stenosis on the grounds that it is difficult to make an asymptomatic patient better, but is Dr Peter Sandercock (30 May, p 1368) aware of the risk of stroke if these patients are left untreated? The results of several studies using ultrasound scanning ${ }^{1-3}$ and intravenous digital subtraction angiography ${ }^{4}$ show that those with severe (more than $75-80 \%$ ) carotid stenosis have a high risk of stroke, transient ischaemic attack, and internal carotid artery occlusion. By contrast, less severe stenoses are associated with a good cerebral prognosis.

The nature of the atherosclerotic plaque is as relevant as its size. The stroke risk of a fibrous, ultrasonically homogeneous plaque is much less than for a plaque distorted by haemorrhage within it. ${ }^{2}$ This is shown as a heterogeneous pattern on ultrasound imaging. The wisdom of aspirin treatment in patients with severe carotid stenosis has been questioned as intraplaque haemorrhage could result from its antiplatelet effects. ${ }^{3}$

What, therefore, should be done to allay the anxieties of a patient with a carotid murmur? If ultrasound scanning shows that the carotid bifurcations are clear the patient may safely be reassured. The findings of a severely stenosed heterogeneous plaque should cause even diehard non-interventionists to think twice. Perhaps the best their patient can hope for is that any cerebral infarct will be preceded by a transient ischaemic attack, which would allow the doctor to reassess the pros and cons of a timely endarterectomy.

\section{I ALDOORI} R N BAIRD

Department of Surgery, Bristol Royal Infirmary, Bristol BS2 8HW

1 Roederer GO, Langlois YE, Jager KA, et al. The natural history of carotid arterial disease in asymptomatic patients with cervical bruits. Stroke 1984;15:605-13.

2 Johnson JM, Kennelly MM, Decesare D, Morgan S, Sparrow A. Natural history of asymptomatic carotid plaque. Arch Surg 1985;120:1010-2.

3 Aldoori MI, Benveniste GL, Baird RN, Horrocks M, Fairgrieve J. Asymptomatic carotid murmur; ultrasonic factors influencing outcome. Brf Surg 1987;74:496-9.

4 Hertzer NR, Flanagan RA, O'Hara PJ, Beven EG. Surgical versus nonoperative treatment of asymptomatic carotid stenosis. Ann
notical versus nonoperative treatmen

\section{Management of Parkinson's disease}

SIR, - We were disturbed to find no mention of surgical thalamotomy in Dr F B Gibberd's clinical algorithm on the management of Parkinson's disease ( 30 May, p 1393). While we accept that the optimal treatment for Parkinson's disease should be effective drug treatment, there is no doubt that the currently available drugs, like thalamotomy, at best alleviate some of the symptoms of the disease and are not curative. The serious inadequacies of long term levodopa treatment are now well known, ${ }^{12}$ and there is a considerable dilemma regarding the timing of such treatment: whether to use it early, when the patient can benefit most, or later, when all other treatments have failed. ${ }^{3}$

Thalamotomy, rather than protracted levodopa treatment, may be the appropriate treatment for the younger or fitter patient with shake, particularly when this is lateralised and in the non-dominant limbs, and it is also appropriate when the complications related to levodopa, particularly dystonic movements, have progressed to the point of incapacity. ${ }^{4}$ The continuing need for thalamotomy has been well argued, ${ }^{5}$ and we have annotated a range of indications in a report to be published in the British fournal of Neurosurgery.

Contemporary thalamotomy, using improved targeting methods and refined lesion making, is much safer than that used before levodopa was introduced, when it was the only form of treatment available and often used inappropriately. For the type of patient described we would suggest that thalamotomy provides a more acceptable option than the toxic complications and insufficient treatment that seem to be the bottom line of the algorithm.

JOHN MILES R M REDFERN

University Department of Neurological Sciences,

Walton Hospital,

Liverpool

1 Barbeau A. High level L-dopa therapy in severely akinetic parkinsonian patients. Twelve years later. In: Rinne UK, Klinger M, Straumn G, eds. Parkinson's disease: curren progress, problems and management. Holland: Elsevier, 1980: 229-39.

2 Portin R, Rinne UK. Neuropsychological response to parkinsonian patients to longterm L-dopa treatment. In: Rinne UK, sonian patients to longterm L-dopa treatment. In: Rinne UK,
Klinger M, Straumn G. Parkinson's disease: current psychiatric problems. Holland: Elsevier, 1980:271-304.

3 Pincus JH. Rationale for early use of levodopa in parkinsonism. Lancet 1986;ii:612-3.

4 Narabayashi H, Yokochi F, Nakajima Y. L-dopa induced dyskinesia and thalamotomy. $\mathcal{F}$ Neurol Neurosurg Psychiatry 1984;47:331-9.

5 Siegfried J. Thalamotomy for parkinsonism. In: Birkmayer W, Hornykiewicz O, eds. Advances in parkinsonism. Basle: Roche, 1976:319-32.

AUTHOR'S REPLY, - I agree with Mr Miles and $\mathrm{Mr}$ Redfern that surgically induced lesions in the brain may be used in the treatment of Parkinson's disease; these were often used in the past, but the indications for thalamotomy are now few and rare. In the algorithm the penultimate box under drug treatment suggests referral to a specialist or neurologist at hospital. The specialist or neurologist would be in a position to consider the rare circumstances in which thalamotomy might be advised. To have included surgery in the algorithm would have given undue weight to surgical procedures. The many methods of managing patients with Parkinson's disease could not be included in a simple algorithm, and I am sure that there are other aspects of the care that, in occasional instances, should be considered.

I am interested to learn that $\mathrm{Mr}$ Miles and $\mathrm{Mr}$ Redfern are to publish a report on the indications for thalamotomy, and I look forward to reading it. It may be that future techniques will make the use of thalamotomy more common, but at present I would expect it to be used on only the rarest occasions.

F B GIBBERD

Westminster Hospital

London SW 1P 2AP

What happens to opiate addicts immediately after treatment?

SIR,-The most important point made by $\mathrm{Dr}$ Michael Gossop and coworkers (30 May, p 1377) concerned the need for aftercare services to support addicts immediately after discharge from hospital.

Those who have stopped misusing drugs on their own, with help from voluntary groups or medical care, often remark on how bored they have become as their days are no longer filled by efforts to obtain and pay for drugs. For some adjustment to a new lifestyle is possible without support, but for others the boredom turns into resentment that, having made some effort to conform to society's wishes to "say no" and "give up drugs," they have to go it alone. Most funding for drug misuse projects has been directed towards health education, prevention, and services to support those with acute problems, and, as far as I am aware, there are 